\title{
Importance of flexible bronchoscopy in decannulation of tracheostomy patients
}

\author{
Importância da broncoscopia flexível na decanulação dos pacientes \\ traqueostomizados
}

Leonardo Brand Rodrigues ${ }^{1,2}$; Tarcizo Afonso Nunes ${ }^{1}$

A B S T R A C T

\begin{abstract}
Objective: To evaluate the importance of flexible bronchoscopy in tracheostomy patients in the process of decannulation to assess the incidence and types of laryngotracheal injury and compare the presence of such lesions with clinical criteria used for decannulation. Methods: We studied 51 tracheostomized patients aged between 19 and 87 years, with tracheal stent for a mean of $46 \pm 28$ days and with clinical criteria for decannulation. They were submitted to tracheostomy tube occlusion tolerance testfor 24 hours, and then to flexible bronchoscopy. We described and classified the diagnosed laryngotracheal changes. We compared the clinical criteria for decannulation indication with the bronchoscopy-diagnosed laryngotracheal injuries that contraindicated decannulation. We identified the factors that could interfere in decannulation and evaluated the importance of bronchoscopy as part of the process. Results: Forty (80.4\%) patients had laryngotracheal alterations. Of the 40 patients considered clinically fit to decannulation, eight $(20 \%)(p=0.0007)$ presented with laryngotracheal injuries at bronchoscopy that contraindicated the procedure. The most frequent laryngeal alteration was vocal cords lesion, in 15 (29\%) individuals, and granuloma, the most prevalent tracheal lesion, in 14 (27.5\%) patients. Conclusion: flexible bronchoscopy showed a large number of laryngotracheal injuries, the most frequent being the vocal cords injury in the larynx and the granuloma in the trachea, which contributed to increase the decannulation procedure safety.
\end{abstract}

Key words: Bronchoscopy. Tracheostomy. Tracheal diseases. Tracheomalacia. Intubation, Intratracheal.

\section{INTRODUCTION}

T racheostomyis performed in about $20 \%$ of patients who are on mechanical ventilation in the intensive care unit ${ }^{1}$. It is indicated to increase comfort and facilitate weaning ${ }^{2}$, reducing the rate of laryngotracheal complications caused by the long permanence of the orotracheal tube ${ }^{3}$, and a s a safe airway in cases of obstruction of the upper airways. However, the presence of tracheostomy causes bronchorrhea, changes in the swallowing mechanism4, increased risk of airway infection and bleeding and hampers vocalization ${ }^{5,6}$. Late complications are diagnosed in $65 \%$ of patients, the most frequent being the granuloma, followed by lesions with high morbidity and mortality such as malacia, stenosis, and vascular and esophageal fistulas s.8. $^{7}$. To avoid these complications, the patient decannulation should be performed as early as possible.

Proper patient assessment before the removal of the cannula has been neglected ${ }^{5,9}$, and the literature is lacking in studies that indicate the criteria and the best time to carry this out ${ }^{10}$. Decannulation failure is characterized when it is necessary to reintroduce the artificial airway in the 48 hours following the removal of the tracheal cannula.
This occurs in up to $5 \%$ of cases and may be associated with acute respiratory failure $e^{6,10}$.

The stringent multidisciplinary clinical evaluation associated with anatomical and physiological assessment of the larynx and trachea contributes to select patients who may be decannulated with more chances of success. The examination by flexible bronchoscopy is important to help decide on the time of decannulation, but is little used and without a detailed protocol ${ }^{10,11}$.

This study aimed to evaluate the importance of flexible bronchoscopy in tracheostomy patients in the process of decannulation to know the incidence and types of laryngotracheal injuries and to compare the presence of such lesions with the clinical criteria used for decannulation.

\section{METHODS}

This was a prospective study in patients in tracheostomy decannulation process at the Hospital Odilon Behrens, in Belo Horizonte-MG. The study was approved by the Departmental Board of the Department of Surgery of FM-UFMG and by the Ethics in Research Committee of

1. Faculty of Medicine, Universidade Federal de Minas Gerais; 2. Hospital Odilon Behrens. 
the Odilon Behrens County Hospital (FR 301247). All patients agreed to participate and signed a free and informed consent.

\section{Sample calculation}

To calculate the sample size, we used the records of the Department of Thoracic Surgery at the Odilon Behrens Hospital. We analyzed data of patients who met clinical criteria for decannulation and were referred to bronchoscopy to evaluate decannulation. Eighteen (72\%) tolerated the occlusion of the cannula, and in three, bronchoscopy diagnosed laryngotracheal injuries contraindicating decannulation (16.6\% failure). So we used the hypothesis test for a proportion that considers the binomial distribution for sample power calculation ${ }^{12}$, considering a power of $80 \%$ with a $5 \%$ significance level and estimated the total size of the sample patients.

\section{Sample characterization}

We studied patients over 18 years, from March 2010 to January 2011, who met the following inclusion criteria: clinical stability, spontaneous ventilation for at least 48 hours; absence of infection at the time of decannulation indication; absence of new surgical procedure in the same hospital; effective coughing and swallowing; Glasgow coma scale $>8$. The patients were examined by a multidisciplinary team including physicians, physical therapists, speech therapists and nurses. In order to be uniformity in the assessments of patients, the multidisciplinary team attended a continuing education program, which extended throughout the period of the survey data collection. The sample comprised 51 patients, 26 female and 25 male, median age 55 years (19-87 years), 22 brown, 19 white and ten black.

Four (7.8\%) patients reported using illicit drugs. Associated diseases were diagnosed in $45(88.2 \%)$ patients, with prevalence of diabetes mellitus (23.5\%). Only seven $(13.72 \%)$ patients had complications related to tracheostomy and overcame the cannulation difficulty $(11.8 \%)$. The most prevalent clinical condition that led to tracheal intubation or tracheostomy was stroke (27.5\%), followed by pneumonia (19.6\%), surgery, trauma, sepsis and airway obstruction (each corresponding to $4 \%$ of patients). Periods of tracheal stent and mechanical ventilation can be seen in figure 1 .

\section{Composition of groups}

Patients who met the inclusion criteria underwent placement of a standard number 4 metal cannula, FadelMed $\circledast$ brand, with an $7.5 \mathrm{~mm}$ internal diameter of, $10 \mathrm{~mm}$ external and $7 \mathrm{~cm}$ length, regardless of the cannula they were previously using. The cannula remained occluded for 24 hours, during which the patients were evaluated for chest expansion, breathing frequency and pattern, lung auscultation, heart rate, pulse and blood pressure. Patients should present with parameters better or equal to the ones

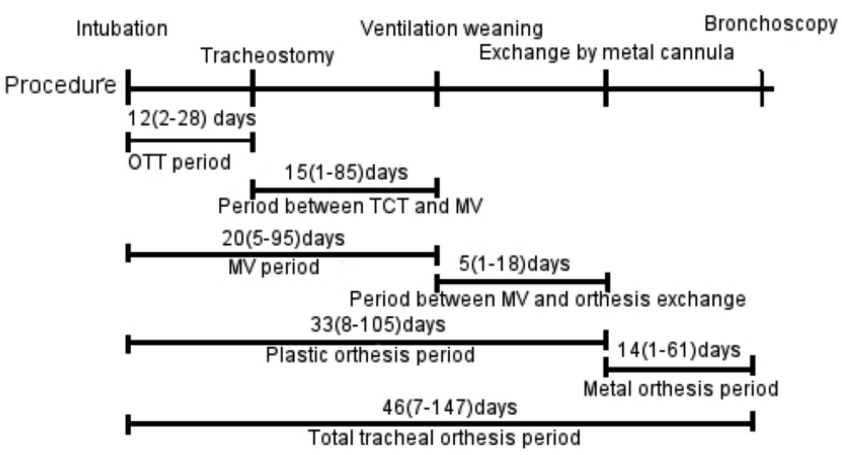

Figure 1-Periods of tracheal cannula and mechanical ventilation.

* OTT - tracheal tube, TCT - tracheostomy, MV - mechanical ventilation.

found before cannula occlusion. Thus, we divided patients in two groups, based on the results of the tracheostomy cannula occlusion: Group A - tolerated; and group B non-tolerated. We considered that patients of group $A$ met the clinical criteria of decannulation and group B did not present these criteria.

\section{Bronchoscopy}

We subjected patients in Groups A and B to laryngotracheobronchial endoscopy by the same examiner after 24 hours of cannula occlusion. The average period between cannula occlusion and the procedure was 1.7 days (1-7 days). The procedure was performed in the bronchoscopy room, with a flexible bronchoscope (Olympus, model BF-P60, optical, 4.9mm working channel external diameter) and local anesthesia with 10\% lidocaine spray at a dose of $30 \mathrm{mg}, 5 \mathrm{ml}$ of lidocaine jelly in the nasal cavity and $1 \%$ lidocaine without vasoconstrictor. The cannula was removed to facilitate tracheal examination, as well as to dynamically assess of forced expiration and inspiration. For dynamic obstructions, such as tracheomalacia, we considered the lowest tracheal diameter during forced expiration. To assess the obstruction of the tracheal lumen, we employed the Cotton classification ${ }^{13}$. Patients with vocal cords bilateral lesions in adduction or subglottic or tracheal obstructiongrade II Cotton or higher (Table 1) were considered endoscopically unfit for decannulation ${ }^{11}$.

Upon completion of bronchoscopy, and based on clinical evaluation, groups $A$ and $B$ were subdivided into four groups: A1, B1, A2 and B2. Patients in group A1 were decannulated after bronchoscopy and remained in hospital under observation for at least 48 hours. Patients in the B1 group were reassessed after clinical improvement, with subsequent decannulation after they tolerated a new occlusion period. Patients in the A2 and B2 groups remained tracheostomized, with an appropriate cannula for each identified lesion, and were referred to the Thoracic Surgery Clinic.

\section{Variables studied and statistical tests}

We described and classified the laryngotracheal lesions identified at bronchoscopy and expressed the result 
Table 1 - Cotton Classification ${ }^{13}$ according to the percentage of tracheal lumen obstruction.

\begin{tabular}{l|l|l}
\hline Grade I & without obstruction- up to 50\% obstruction & \\
\hline Grade II & $51 \%$ to $70 \%$ obstruction & \\
\hline Grade III & $71 \%$ to $99 \%$ obstrution & \\
\hline Grade IV & complete obstruction & \\
\hline
\end{tabular}

as percentage. We then compared patients' groups formed by decannulation clinical and bronchoscopic criteria.

The highest decannulation failure rate described among patients who fulfilled the clinical criteria for decannulation is $5 \%{ }^{9}$. Bilateral lesions of the vocal cords and / or tracheal obstruction greater than Cotton grade II at bronchoscopy are at higher risk of respiratory failure without the use of tracheostomy. Hence, we compared the evolution ofgroups $A 1, A 2, B 1$ and $B 2$ by employing Fisher's test ${ }^{14}$.

Bronchoscopy is the best test for diagnosing laryngotracheal changes that contraindicate decannulation, so we carried out the analysis of clinical efficacy criteria by comparison between the predictive value found after bronchoscopic validation and the one described in the literature $-95 \%$ decannulation success. We considered null hypothesis $\left(\mathrm{H}_{0}\right)$ the positive predictive value of clinical criteria equal or greater than $95 \%$, and as an alternative hypothesis $\left(\mathrm{H}_{\star}\right)$ the positive predictive value being lower than $95 \%{ }^{15}$.

\section{RESULTS}

Nine $(17.6 \%)$ patients had no laryngotracheal changes. In 42 (82.4\%) lesions were diagnosed, 20 with (39.2\%) one and 22 (43.1\%) with two or more lesions, as described: paresis or paralysis of the vocal cord in adduction or abduction in 15 (29\%) patients, eight $(15.7 \%)$ having bilateral lesions. All of them were associated with paresis of the corresponding hemilarynx; scar tissue suggesting granuloma in $14(27.5 \%)$ patients, all located in the tracheostoma, determining grade I obstruction; depression of the anterior wall of the tracheostoma in six $(11.8 \%)$ patients, determining tracheal grade I obstruction; tracheostoma in improper anatomical position, lateral to the midline of the trachea anterior wall in ten (19.6\%) patients; laryngotracheal obstruction in 22 $(43.1 \%)$, tracheomalacia in $12(60 \%)$, five $(25 \%)$ laryngotracheomalacias and five (25\%) stenoses. According to the Cotton classification, we foundthe following degrees of obstruction: Nine $(17.6 \%)$ grade I, nine $(17.6 \%)$ grade II, two (3.9\%) grade III and two (3.9\%) grade IV.

Forty patients tolerated cannula occlusion, but bronchoscopy diagnosed laryngotracheal injuries in eight $(20 \%)$, for whom we contraindicated decannulation. Of the 11 patients who did not tolerate occlusion of the cannula, bronchoscopy showed no injuries that prevented decannulation in two (18.2\%). Ten (19.6\%) patients benefited from bronchoscopy, since it decreased the risk of decannulation failure in eight and avoided cannula permanence in two (Table 2). By employing bronchoscopy as one decannulation criteria, we found $20 \%$ of laryngotracheal injuries that could determine failure in the decannulation process. Thus, considering the binomial distribution, we rejected the null hypothesis that $95 \%$ of patients who meet the clinical criteria tolerate decannulation $(p<0.007)$. The decannulated patients who met the clinical and bronchoscopic criteria for decannulation had no complications and required no new tracheal cannula.

\section{DISCUSSION}

In the period when we conducted the survey, 240 patients were submitted to tracheostomy and only 51 $(21.3 \%)$ met the clinical criteria for decannulation ${ }^{6,10}$. This variation can be explained by the difference in the method used for patients inclusion in the various studies, as there was difference in the number and types of clinical criteria used to define the patient as clinically fit to decannulation 5,6,10,16. While in these studies patients remained with tracheostomy for prolonged periods (average of up to 147 days $)^{17}$, in this study the average time was 33 days.

Lesions that affect $50 \%$ or more of the tracheal diameter are a contraindication to decannulation. From this degree of obstruction on, marked changes in pulmonary function tests may occur, with clinical repercussions ${ }^{10,18,19}$. One study, however, considers thatobstructions are significant when affecting $20 \%$ of the tracheal diameter ${ }^{17}$. 
Table 2 - Description of patients fit fordecannulation through clinical criteria, but contraindicated by Bronchoscopy $(n=8)$.

\begin{tabular}{|c|c|c|c|c|c|}
\hline Patients & $\begin{array}{c}\text { Age } \\
\text { (years) }\end{array}$ & $\begin{array}{c}\text { Associater } \\
\text { Diseases }\end{array}$ & $\begin{array}{l}\text { Clinical conditions } \\
\text { that prompted } \\
\text { orotracheal intubation } \\
\text { or tracheostomy }\end{array}$ & $\begin{array}{l}\text { Plastic } \\
\text { Orthosis } \\
\text { Period } \\
\text { (days) }\end{array}$ & $\begin{array}{l}\text { Bronchoscopyic laryngotracheal } \\
\text { changes } \\
\text { contraindicating decannulation }\end{array}$ \\
\hline 1 & 26 & - & Convul & 74 & Bilateral paresi \\
\hline 2 & 8 & DM, SA- & Trauma & 105 & acheor \\
\hline 3 & 5 & SAH, AMI & Airway obstruction & 24 & acheor \\
\hline 4 & 88 & $\mathrm{DM}, \mathrm{SAH}, \mathrm{COPD}, \mathrm{CRF}, \mathrm{CHF}$ & STROKE & 26 & Il tracheomalacia \\
\hline 5 & 55 & DM, SAH & Sepsis & 41 & Grade II tracheomalacia \\
\hline 6 & 53 & DM, SAH, muscular dystrophy & Pneumonia & 49 & Grade II tracheomalacia \\
\hline 7 & 70 & SAH, Obesity & STROKE & 30 & Grade II tracheomalacia \\
\hline 8 & 64 & $\mathrm{COPD}, \mathrm{CHF}$ & Decompensated CHF & 25 & Bilateral paresis of vocal cords in adduction \\
\hline
\end{tabular}

DM -diabetes mellitus; SAH -systemic arterial hypertension; COPD - chronic obstructive pulmonary disease; AMI -acute myocardial infarction; CRF - chronic renal failure; CHF -congestive heart failure; STROKE -stroke.

In adults, the tracheal diameter It is $20 \mathrm{~mm}$ in womenand $23 \mathrm{~mm}$ in men ${ }^{8}$, which is why we used a number 4 metal cannula with $10 \mathrm{~mm}$ external diameter at the time of decannulation, since when occluded, It represents about $50 \%$ of tracheal lumen obstruction.

We consider flexible bronchoscopy necessary before decannulation, like other authors ${ }^{17,20}$, due to the method's sensitivity in diagnosing laryngotracheal anatomical and functional lesions ${ }^{21}$ that are common in tracheostomy patients. This test is considered safe and its complication rates are less than $1 \%{ }^{22}$. In the present study there were no complications that prevented laryngotracheal assessment or that worsened patients' clinical status.

Granulomas were found in $27.5 \%$ of patients, all in the tracheostoma region, without determining airflow obstruction (Cotton Grade I). We found laryngotracheomalacias and laryngotracheal stenoses in $33.3 \%$ and $9.8 \%$ of patients, respectively, regardless of the degree of obstruction they caused. Some authors have observed similar findings when using flexible bronchoscopy as a criterion for decannulation 7,17 .

Lesions that determined Cotton grades II, III and IV obstructions were diagnosed in $25.5 \%$ of patients. We did not find fistulas or bulky bleeding, which is in accordance with the literature ${ }^{7,17}$. We found changes in vocal cords in $29.4 \%$ of patients, in eight patients the lesions were bilate$\mathrm{ral}$, and in $87.5 \%$ of the lesions the vocal cords were in adduction.

Patients who met the decannulation clinical criteria, but not the bronchoscopic ones, could have been decannulated without evolving with respiratory failure. One should consider that patients confined to bed or who, for other reasons, did not perform physical exertion, and might not present respiratory failure, even with obstructions larger than $50 \%$ of the tracheal lumen or bilateral vocal cord paresis in adduction. This fact may have contributed to explain the difference between the $20 \%$ considered as failure, found in this study, and $5 \%$ described in the literature ${ }^{17}$. However, we considered that the decannulation of specific cases would be better evaluated after prolonged follow-up of the patient and recovery of symptoms, which determined the alternative airway maintenance. Considering the clinical criteria for the decannulation, bronchoscopy benefited ten (19.6\%) patients, since it contraindicated decannulation in eight and identified two who did not have lesions that would contraindicate decannulation by clinical criteria. One study ${ }^{18}$ found that only the clinical criteria would be sufficient and safe to indicate decannulation. However, the author has employed a method different from ours regarding the sample, the inclusion criteria, the cannula to be occluded with large diameter, the difference in the description of laryngotracheal injuries, as well as the different bronchoscopy diagnoses. Thus, the comparison of the results rendered inadequate.

Clinical circumstances which led to tracheal intubation or tracheostomy, associated diseases and age did not influencedecannulation, which is in line with the results of the literature ${ }^{17}$. Nonetheless, the number of patients was insufficient for statistical evaluation on these relationships. Patients with diabetes mellitus, however, were more likely to decannulation contraindication by bronchoscopy, even when meeting the clinical criteria ( $p=$ 0.04). This fact can be explained by changes in scarring mechanisms, since the four diabetic patients with favorable decannulation clinical criteria had unfavorable bronchoscopic ones due to the presence of tracheomalacia. We did not find this data in the literature.

Among the 15 patients with vocal cord lesions and 22 who presented laryngotracheal stenosis, the average time they remained with the tracheal tube was 10.06 days. 
Even this being a long tracheal tube period, they showed no statistical difference when compared with patients without injuries. There are reports that the intubation time increases the number of laryngotracheal injuries and, therefore, the occurrence of decannulation failure, but there is controversy ${ }^{17,23}$ and the number of patients of this study was insufficient to contribute towards clarifying such doubts. Randomized studies are needed to better identify the factors that interfere in decannulation ${ }^{17}$. Whereas not only the tracheal tube, but any orthesis, can cause laryngotracheal damage, upon analysis of the periods of tracheal cannula use evaluated in this study, only the longest period of plastic orthesis use (tracheal tube plus tracheostomy plastic cannula) related significantly with the diagnosis of laryngotracheal injuries at bronchoscopy $(p=0.04)$. However, since this period interacts with other variables, such as the period between the tracheostomy and the end of mechanical ventilation, mechanical ventilation time, period of endotracheal tube use, period oftracheostomy plastic cannula use, and total orthesis period, including the period of metallic cannula (Figure 1), we used multiple logistic regression to the group of variables related to the period of tracheal cannula usage and which had significance less than $0.25^{24}$. The goal was to determine whether one of the periods of total plastic orthesis alone could be related as cause and effect of the existence of laryngotracheal injuries contraindicating decannulation. The adjustment of logistic regression was affected by multicollinearity (positive correlation between the measured time variables) and none of the variables were significant.
One limitation of this study is the use of subjective criteria for classifying injuries that cause airflow obstruction. The Cotton classification ${ }^{13}$ is based on direct endoluminal observation, without a specific instrument to measure the area of tracheal lumen obstruction. Another limitation encountered was the difficulty of patients' monitoring after hospital discharge. However, most of the complications that cause decannulation failure occur in the first $48 h^{9,25}$, during which the patients in this study were hospitalized. The number of research subjects was sufficient to assess the benefit of performing bronchoscopy as a decannulation criterion. Nevertheless, we could not identify the factors that make bronchoscopy indispensable or dispensable for decannulation. In this paper we developed a protocol using clinical criteria that are consensus among most researchers, together with the most appropriate method for assessing the laryngotracheal region $5,6,10,26$, aimed at providing safety to the patient at the time of decannulation. More prospective studies are needed to determine the usefulness of bronchoscopy in the evaluation of decannulation. Methods are needed to describelaryngotracheal injuries in an objective and standardized way, possibly altering the bronchoscopic decannulation criteria by identifying which ones can actually be cause of failure.

Flexible bronchoscopy showed a large number of laryngotracheal injuries, the more frequent being in the vocal cords, in the larynx and the tracheal granuloma, which contributed to increase the safety of the decannulation procedure.

\title{
R E S U M O
}

\begin{abstract}
Objetivo: avaliar a importância do emprego, da broncoscopia flexível nos pacientes traqueostomizados em vias de decanulação para conhecer a incidência e os tipos de lesões laringotraqueais e comparar a presença destas lesões com os critérios clínicos utilizados para a decanulação. Métodos: foram estudados 51 pacientes, com idade entre 19 e 87 anos, traquestomizados, com critérios clínicos de decanulação e com tempo médio de órtese traqueal de $46 \pm 28$ dias. Foram submetidos ao teste de tolerância à oclusão da cânula de traqueostomia por 24 horas, seguida da realização da broncoscopia flexível. As alterações laringotraqueais diagnosticadas foram descritas e classificadas. Comparou-se a indicação de decanulação por critérios clínicos com o diagnóstico de lesões laringotraqueais à broncoscopia que contraindicavam a decanulação. Identificaram-se os fatores que poderiam interferir na decanulação e avaliou-se a importância da broncoscopia como parte do processo. Resultados: Apresentaram alterações laringotraqueais, 40 pacientes $(80,4 \%)$. Dos 40 pacientes considerados clinicamente aptos à decanulação, oito $(20 \%)(p=0,0007)$ apresentaram lesões laringotraqueais à broncoscopia que contraindicaram o procedimento. A alteração laríngea mais frequente foi lesão de pregas vocais em 15 (29\%) e o granuloma, a lesão traqueal mais prevalente em 14 (27,5\%) pacientes. Conclusão: a broncoscopia flexível evidenciou um número elevado de lesões laringotraqueais, sendo mais prevalentes a lesão de pregas vocais na laringe e o granuloma na traqueia, que contribuiu para aumentar a segurança do procedimento de decanulação.
\end{abstract}

Descritores: Procedimentos Cirúrgicos Broncoscópicos. Traqueostomia. Traqueopatias. Traqueomalácia. Intubação Intratraqueal

\section{REFERENCES}

1. Esteban A, Anzueto A, Alía I, Gordo F, Apezteguía C, Pálizas F, et al. How is mechanical ventilation employed in the intensive care unit? An international utilization review. Am J Respir Crit Care Med. 2000;161(5):1450-8.
2. Blot F, Melot C; Commission d'Epidémiologie et de Recherche Clinique. Indications, timing, and techniques of tracheostomy in 152 French ICUs. Chest. 2005;127(4):1347-52.

3. Castella $X$, Gilabert J, Torner F. Laryngeal damage from intubation. Chest. 1990;98(3):776-7. 
4. Romero CM, Marambio A, Larrondo J, Walker K, Lira MT, Tobar $\mathrm{E}$, et al. Swallowing dysfunction in nonneurologic critically ill patients who require percutaneous dilatational tracheostomy. Chest. 2010;137(6):1278-82.

5. Heffner JE. Tracheostomy decannulation: marathons and finish lines. Crit Care. 2008;12(2):128.

6. Ceriana P, Carlucci A, Navalesi P, Rampulla C, Delmastro M Piaggi $G$, et al. Weaning from tracheotomy in long-term mechanically ventilated patients: feasibility of a decisional flowchart and clinical outcome. Intensive Care Med. 2003;29(5):845-8.

7. Epstein SK. Late complications of tracheostomy. Respir Care. 2005;50(4):542-9.

8. Grillo HC. Surgery of the trachea and bronchi. Hamilton: BC Decker; 2004.

9. Pierson DJ. Tracheostomy and weaning. Respir Care. 2005;50(4):526-33.

10. Stelfox HT, Crimi C, Berra L, Noto A, Schmidt U, Bigatello LM, et al. Determinants of tracheostomy decannulation: an international survey. Crit Care. 2008;12(1):R26.

11. Rumbak MJ, Walsh FW, Anderson WM, Rolfe MW, Solomon DA. Significant tracheal obstruction causing failure to wean in patients requiring prolonged mechanical ventilation: a forgotten complication of long-term mechanical ventilation. Chest. 1999:115(4):1092-5.

12. Magalhães MN, Lima A. Noções de probabilidade e estatística. $5^{a}$. ed. São Paulo: Edusp; 2002.

13. Cotton RT. Pediatric laryngotracheal stenosis. J Pediatr Surg. 1984;19(6):699-704.

14. Agresti A. Categorical data analisys. Hoboken: John Wiley and Sons; 2002.

15. Shapiro SS, Wilk MB. An analysis of variance test for normality (complete samples). Biometrika. 1965;52(3-4):591-611.

16. Stelfox HT, Hess DR, Schmidt UH. A North American survey of respiratory therapist and physician tracheostomy decannulation practices. Respir Care. 2009;54(12):1658-64.

17. Law JH, Barnhart K, Rowlett W, de la Rocha O, Lowenberg S. Increased frequency of obstructive airway abnormalities with longterm tracheostomy. Chest. 1993;104(1):136-8.
18. Rumbak MJ, Graves AE, Scott MP, Sporn GK, Walsh FW, Anderson $W M$, et al. Tracheostomy tube occlusion protocol predicts significant tracheal obstruction to air flow in patients requiring prolonged mechanical ventilation. Crit Care Med. 1997;25(3):4137.

19. Raghuraman G, Rajan S, Marzouk JK, Mullhi D, Smith FG. Is tracheal stenosis caused by percutaneous tracheostomy different from that by surgical tracheostomy? Chest. 2005;127(3):879-85.

20. Lee TS, Wu Y. Bedside fiberoptic bronchoscopy for tracheostomy decannulation. Respir Med. 1995;89(8):571-5.

21. Carden KA, Boiselle PM, Waltz DA, Ernst A. Tracheomalacia and tracheobronchomalacia in children and adults: an in-depth review. Chest. 2005;127(3):984-1005.

22. Abraham GE 3rd, Sumrall BH, Bowling MR. The air apparent: a rare complication during flexible bronchoscopy. Am J Med Sci. 2011;341(3):243-5.

23. Bishop MJ. The timing of tracheotomy. An evolving consensus. Chest. 1989;96(4):712-3.

24. Hosmer DW, Lemeshow S. Applied logistic regression. 2nd ed. New York: Wiley; 2000

25. Bach JR, Saporito LR. Criteria for extubation and tracheostomy tube removal for patients with ventilatory failure. A different approach to weaning. Chest. 1996;110(6):1566-71

26. Marchese S, Corrado A, Scala R, Corrao S, Ambrosino N; Intensive Care Study Group, Italian Association of Hospital Pulmonologists (AIPO). Tracheostomy in patients with long-term mechanical ventilation: a survey. Respir Med. 2010;104(5):749-53.

Received on 07/05/2014

Accepted for publication 30/06/2014

Conflict of interest: none.

Source of funding: none.

Address for correspondence:

Leonardo Brand Rodrigues

E-mail: leotoracica@gmail.com 